Originalartikkel

\title{
Legevakt for alders- og sykehjemmene
}

\begin{abstract}
Sammendrag
Bakgrunn. Effektivisering av legevakttjenesten har sannsynligvis medført redusert tilgjengelighet til legevakttjenester for sykehjemspasienter mange steder. I Bergen ble det i mars 2006 etablert en egen vaktordning for alders- og sykehjemmene samt hjemmeboende med spesielle behov. Vi ønsket å evaluere denne ordningen etter ett års drift.
\end{abstract}

Materiale og metode. Karakteristika for brukerne av vaktordningen og tidspunkt for henvendelse til vakten ble samlet inn prospektivt. Data om de ulike alders- og sykehjemmene ble også innhentet.

Resultater. Det var 926 henvendelser til vaktordningen dette året, hvorav over halvparten førte til sykebesøk. Pneumoni og urinveisinfeksjon var de hyppigste enkeltdiagnosene. God sykehjemslegedekning medførte ikke færre henvendelser til vaktordningen. Det ble ikke påvist statistisk sammenheng mellom antall henvendelser og det totale antall senger eller antallet korttidssenger ved sykehjemmene.

Fortolkning. Aktiviteten i vaktordningen var moderat det første driftsåret. Sykehjemmenes bruk av ordningen bestemmes av andre faktorer enn antall senger og legeressurser ved sykehjemmene.

\section{Knut Steen}

knut.steen@bergen.kommune.no

Marta Mjeldheim

Bergen legevakt

Vestre Strømkaien 19

5008 Bergen

\section{Steinar Hunskår}

Nasjonalt kompetansesenter for legevaktmedisin og

Seksjon for allmennmedisin

Institutt for samfunnsmedisinske fag

Universitetet i Bergen

Legevakttjenesten i Norge er blitt effektivisert de senere årene med flere pasientkonsultasjoner i legevaktens lokaler og færre sykebesøk $(1,2)$. Dette har sannsynligvis medført redusert tilgjengelighet til legevakttjenester for pasienter som har vanskelig for å ta seg frem til legevaktlokalet på egen hånd. Legeforeningens gjennombruddsprosjekt for sykehjemsmedisin har i en idédugnad foreslått en egen legevaktordning for sykehjemmene (3), og en nylig publisert studie fra Røde Kors Sykehjem i Bergen konkluderer med at egen vaktordning for leger ved sykehjemmet er en viktig del av pasientbehandlingen (4).

Legevakttjenesten i Bergen ble omorganisert i 1998 og sykebesøksformidlingen ble da nedlagt. Etter omorganiseringen blir sykebesøk fra legevakten utført bare etter streng medisinsk indikasjon. Antallet årlige sykebesøk fra legevakten i Bergen har i løpet av det siste tiåret sunket fra rundt 25000 til noen få hundre (legevaktsjef Frank van Betten, personlig meddelelse). På landsbasis gjøres det årlig 97000 sykebesøk i forbindelse med legevakt (5), mens det i Oslo gjøres ca. 19000 slike besøk (6). Der er ordningen hovedsaklig et tilbud til eldre og alvorlig syke pasienter (7).

For å bedre kvaliteten på og tilgjengeligheten til legevakttjenester til alders- og sykehjemmene samt hjemmeboende med spesielle medisinske behov, som for eksempel terminale pasienter og multifunksjonshemmede, ble en egen vaktordning opprettet av Bergen kommune fra mars 2006. Vaktlegen har kontor i legevaktens lokaler, og legevaktens telefonsentral og journalsystem benyttes. Henvendelsene til vaktordningen kvalitetssikres ved at det er sykepleiere på aldersog sykehjemmene eller i hjemmesykepleien som melder behov for bruk av ordningen til legevaktsentralen. Dette kan gjøres hele døgnet. En egen vaktlege har vakt fire timer hver ettermiddag i uken og seks timer hver dag på dagtid i helg eller høytid. Legene til denne vaktordningen rekrutteres primært blant leger ansatt ved alders- og sykehjemmene. Denne legen vurderer adekvate medisinske tiltak, inkludert behovet for sykebesøk, etter ny telefonisk kontakt, fortrinnsvis med innringer.

Vi ønsket å evaluere vaktordningen etter ett års drift. Vi ønsket spesielt å se på aktivitetsnivået og om forhold ved aldersinstitusjonene var av betydning for brukshyppigheten av vaktordningen.

\section{Materiale og metode}

Pasienter til undersøkelsen ble fortløpende registrert i legevaktsentralen fra listen over henvendelser til vaktordningen det første driftsåret (14.3. 2006-13.3. 2007), mens dataene om de ulike pasientene ble hentet fra deres journaler ved «sykehjemslegevakten» (legevaktens journalarkiv brukes) og i anonymisert form overført til statistikkprogram for videre analyse. Således innhentet man kun data som normalt forefinnes i en legevaktjournal. Følgende data ble prospektivt samlet inn: Alder og kjønn på pasient, tidspunkt for henvendelse, bosted (hjemmeboende eller alders- eller sykehjemspasient, navn på institusjon), kontaktform (sykebesøk eller kun telefonkonsultasjon), hoveddiagnose (ICPC-kode), og om pasienten ble innlagt i sykehus etter sykebesøk.

Data om alders- og sykehjemmene i Bergen (aldershjem eller sykehjem, antall senger, herav antall korttidssenger og legedekning) ble innhentet fra kommunen og kvalitetssikret ved direkte henvendelse til institusjonene. Totalt var det 32 sykehjem med 2278 senger, inkludert 88 senger ved aldershjemsdelen til tre institusjoner med både alders- og sykehjemsdel. I henvendelser fra disse tre institusjonene var det $i$ undersøkelsen ikke tydelig skilt mellom pasienter fra alders- eller sykehjemsdelen. Det var i praksis ikke mulig å avgjøre hvor stor

\section{Hovedbudskap}

- Fra 2006 har man hatt en egen vaktordning for sykehjem i Bergen

- Hyppigste årsak til bruk av vaktordningen var infeksjonsdiagnoser

- Sykehjemmenes bruk av vaktordningen bestemmes av andre forhold enn legedekning og antall sykehjemssenger 
Tabell 1 Oversikt over de hyppigste ICPC-diagnosene (antall og prosent) til pasienter som henvender seg til «sykehjemslegevakten» $(n=880)$. IKA = ikke klassifisert annet sted

\begin{tabular}{llrr} 
& & $N$ & $\%$ \\
\hline R81 & Pneumoni & 135 & 15 \\
\hline U71 & Cystitt/urinveisinfeksjon IKA & 127 & 14 \\
\hline A96 & Død/dødsfall IKA & 96 & 11 \\
\hline A13 & Engstelig for behandling & 17 & 2 \\
\hline K77 & Hjertesvikt & 16 & 2 \\
\hline K90 & Hjerneslag & 15 & 2 \\
\hline U8 & Urinretensjon & 13 & 2 \\
\hline A78 & Infeksjonssykdom IKA & 13 & 2 \\
\hline R95 & Kronisk obstruktiv lungesykdom & 12 & 1 \\
\hline A99 & Helseproblem/sykdom IKA & 11 & 1 \\
\hline Alle andre diagnoser & 425 & 48 \\
\hline
\end{tabular}

andel av tilsynslegetiden som ble brukt på henholdsvis aldershjemsdelen og sykehjemsdelen ved institusjonen. Aldershjemsavdelingen til disse institusjonene ble derfor ikke skilt ut fra sykehjemsdelen i analysen av materialet. Et større sykehjem (174 senger) der institusjonens egne leger hadde formalisert bakvakt hele døgnet (4), ble ekskludert fra undersøkelsen (ingen henvendelser til vaktordningen). Totalt var det seks rene aldershjem med 179 senger. Videre var det $\mathrm{i}$ alt 397 korttidssenger fordelt på 18 sykehjem og fire aldershjem, hvorav 47 var korttidsplasser ved aldershjem.

Statistikkprogrammet Epi Info ble brukt til analyse av dataene. Statistisk signifikans ble satt til $\mathrm{p}<0,05$.

\section{Resultater}

Totalt ble det registrert 926 henvendelser til vaktordningen i løpet av det første driftsåret.
566 av disse gjaldt kvinnelige pasienter $(61 \%)$. I gjennomsnitt var det 2,5 henvendelser per vakt. Kvinner var eldre enn menn (gjennomsnittsalder kvinner 86 år (SD 8 år), gjennomsnittsalder menn 81 år (SD 10 år), $\mathrm{p}<0,01)$. Pasienter ved alders- og sykehjemmene var eldre enn de hjemmeboende (alders- og sykehjem: gjennomsnittsalder 85 år (SD 8 år) versus hjemmeboende: gjennomsnittsalder 74 år (SD 16 år), p < 0,01). De fleste henvendelsene kom fra sykehjemmene $(\mathrm{n}=777(84 \%))$, etterfulgt av aldershjemmene $(\mathrm{n}=68(7 \%))$, hjemmesykepleien $(\mathrm{n}=66$ $(7 \%))$ og andre/ukjent $(\mathrm{n}=15(2 \%))$.

Vaktordningen ble brukt mest $\mathrm{i}$ helgene, med over $60 \%$ av alle henvendelser på ukens tre siste dager. Lørdag var dagen med flest henvendelser $(n=248 \quad(27 \%))$. På ukens fire første dager var det gjennomsnittlig 1,7 henvendelser per vakt, mens det i helgene var gjennomsnittlig 3,5 henvendelser

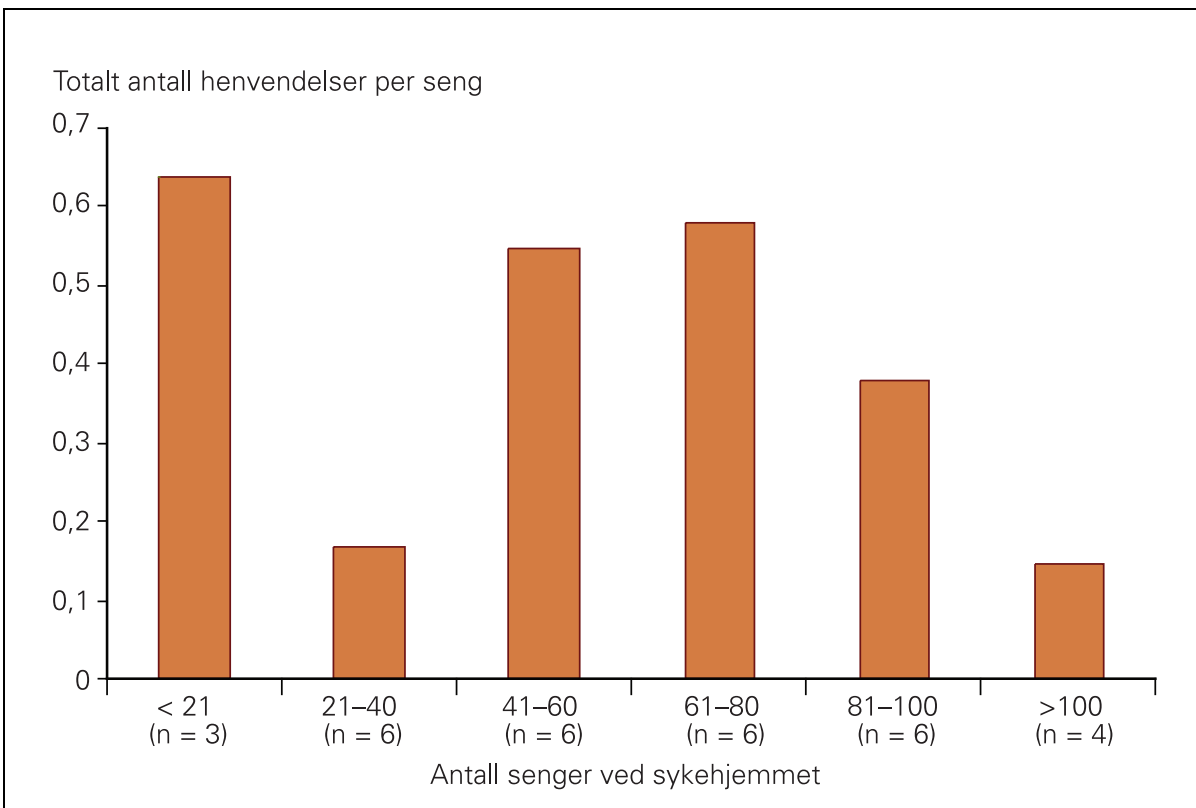

Figur 1 Gjennomsnittlig antall henvendelser per sykehjem til vaktordningen etter det totale antall senger ved sykehjemmene per vakt. Det var flest henvendelser om sommeren (juli: $\mathrm{n}=100(11 \%)$ og august: $\mathrm{n}=91$ $(10 \%)), o g$ færrest i månedene rundt årsskiftet (desember: $\mathrm{n}=52(6 \%)$ og januar: $\mathrm{n}=60$ $(7 \%))$. Det ble utført 534 sykebesøk $(58 \%$ av alle henvendelser), 96 av disse til døde pasienter (syning av lik). Totalt ble 121 pasienter innlagt i sykehus (121 av 438 levende pasienter $(28 \%))$.

880 hoveddiagnoser ble registrert. Tabell 1 viser de ti hyppigste diagnosene. Pneumoni var den vanligste enkeltdiagnosen, etterfulgt av urinveisinfeksjoner. Innen ICPC-kodesystemet var A-kapitlet (allment og uspesifisert) det største enkeltkapitlet $(n=200)$.

Antall henvendelser til vaktordningen fra sykehjemmene var $0-65$. Vi fant ikke statistisk sammenheng mellom sykehjemmenes størrelse og antallet henvendelser til vaktordningen $(p=0,21)$ (fig 1$)$. To store sykehjem utmerket seg med få henvendelser. Blant de sykehjemmene som disponerte korttidssenger $(\mathrm{n}=18)$ fant vi ikke statistisk sammenheng mellom antallet korttidssenger og antallet henvendelser $(p=0,57)$ (fig 2).

Antall ukentlige legetimer per pasient ved sykehjemmene var 0,08-1,98 timer (gjennomsnitt 0,40 , median 0,30 ). Antall ukentlige legetimer per pasient ved aldershjemmene var 0,10-0,16 timer (gjennomsnitt 0,12 , median 0,12). Dersom all legevakttid i ordningen er aktiv og bare brukes på aldersog sykehjemspasienter, tilsvarer dette 0,01 time per pasient $\mathrm{i}$ uken.

Grunnet to sykehjem med god legedekning (1,17 og 1,98 ukentlige legetimer per pasient) og mange henvendelser til vaktordningen (65 og 58 henvendelser), var det en positiv korrelasjon mellom legedekning på sykehjemmene og antallet henvendelser $(p=0,04)$. Ekskluderes disse to sykehjemmene fra analysen, var det ingen statistisk sammenheng mellom legedekningen og antallet henvendelser til vaktordningen $(p=0,13)$.

Antall henvendelser fra aldershjemmene var 3-29, mens legedekningen her var rimelig ensartet. Statistisk analyse er ikke utført grunnet få aldershjem $(n=6)$.

\section{Diskusjon}

Totalt sett var aktiviteten til vaktordningen moderat det første driftsåret, med 2,5 henvendelser per vakt, hvorav drøyt halvparten førte til sykebesøk. Vi tror dette skyldes at ordningen initialt var lite kjent blant mange potensielle brukere. Imidlertid er sykebesøk til eldre og pleietrengende pasienter tidkrevende, og data fra denne vaktordningen kan ikke umiddelbart sammenliknes med den vanlige legevakttjenesten. Alders- og kjønnsfordelingen til brukerne av vaktordningen avspeiler den generelle alders- og kjønnsfordelingen til brukerne av pleie- og omsorgstjenester (8).

Den nye særvaktordningen er en integrert del av legevaktens totale tilbud. Generelt er legevakt et sikkerhetsnett for medisinske problemer som ikke kan vente til de faste legene er tilgjengelige. Både den økte aktiviteten i 
helger og ferier og det store antallet infeksjonsdiagnoser indikerer at vaktordningen for sykehjemmene i Bergen har fungert etter allmenne prinsipper for legevakt, mens vaktordningen for leger ved Røde Kors Sykehjem i Bergen synes å være mer integrert i det totale behandlingstilbudet ved sykehjemmet. Således er en betydelig del av aktiviteten til vaktordningen ved Røde Kors Sykehjem rådgivning og informasjon til pårørende og personale (4). Ressursbruken til vaktordningen ved sykehjemmet avspeiler dette i tillegg til ressurskrevende spesialavdelinger ved Røde Kors Sykehjem (palliativ avdeling: 0,32 legetimer per pasientuke, korttidsavdeling: 0,07 legetimer per pasientuke og langtidsavdeling: 0,03 legetimer per pasientuke) (4). Til sammenlikning har vaktordningen for alders- og sykehjemmene i Bergen ca. 0,01 legetime per pasientuke, mens Forum Sykehjemsmedisin anbefaler 0,05 legetimer per pasientuke til vaktberedskap (9).

Etter henvendelse til vaktordningen ble det kjørt sykebesøk til drøyt halvparten av pasientene, noe som er omtrent ti ganger høyere andel enn ved legevakt på landsbasis $(5,4 \%)(5)$. Men en høy sykebesøksaktivitet til gamle og pleietrengende pasienter var en klar målsetting før oppstart av vaktordningen. Omtrent en firedel av pasientene (døde pasienter ekskludert) som ble vurdert i sykebesøk, ble innlagt i sykehus. Det anser vi som en forholdsvis høy andel sykehusinnleggelser, og understreker at pasientenes medisinske tilstand var preget av relativt høy alvorlighetsgrad.

Det ble ikke systematisk samlet inn data om bruk av ambulansetransport eller innleggelsesfrekvens i sykehus for alders- og sykehjemspasienter før og etter innføring av denne særvaktordningen. Data fra undersøkelsen med egen døgnkontinuerlig vaktordning for leger ved Røde Kors Sykehjem viser at en del sykehusinnleggelser kan unngås med en slik vaktordning (4). Det er også vårt subjektive inntrykk at vaktordningen for alle sykehjem i Bergen har medført reduksjon i både ambulansetransport og sykehusinnleggelser. En vaktordning med geriatrisk kompetanse som målretter en samfunnsdyr virksomhet som sykebesøk mot syke- og aldershjemspopulasjonen, tror vi totalt sett er god samfunnsøkonomi og samtidig en styrking av det medisinske tilbudet til denne pasientgruppen. Denne modellen for en egen legevaktordning for alders- og sykehjem mener vi egner seg for større byer med et stort press på den vanlige legevakten og et betydelig volum på henvendelser fra alders- og sykehjemmene.

Undersøkelsen viser stor variasjon i bruk av ordningen mellom de ulike alders- og sykehjemmene. For sykehjemmene kunne vi ikke påvise noen statistisk signifikant sammenheng mellom antall henvendelser til vaktordningen og det totale antall senger eller antallet korttidssenger. En usikkerhetsfaktor her er imidlertid i hvilken grad registrerte korttidssenger og permanente plasser

Totalt antall henvendelser per korttidsseng

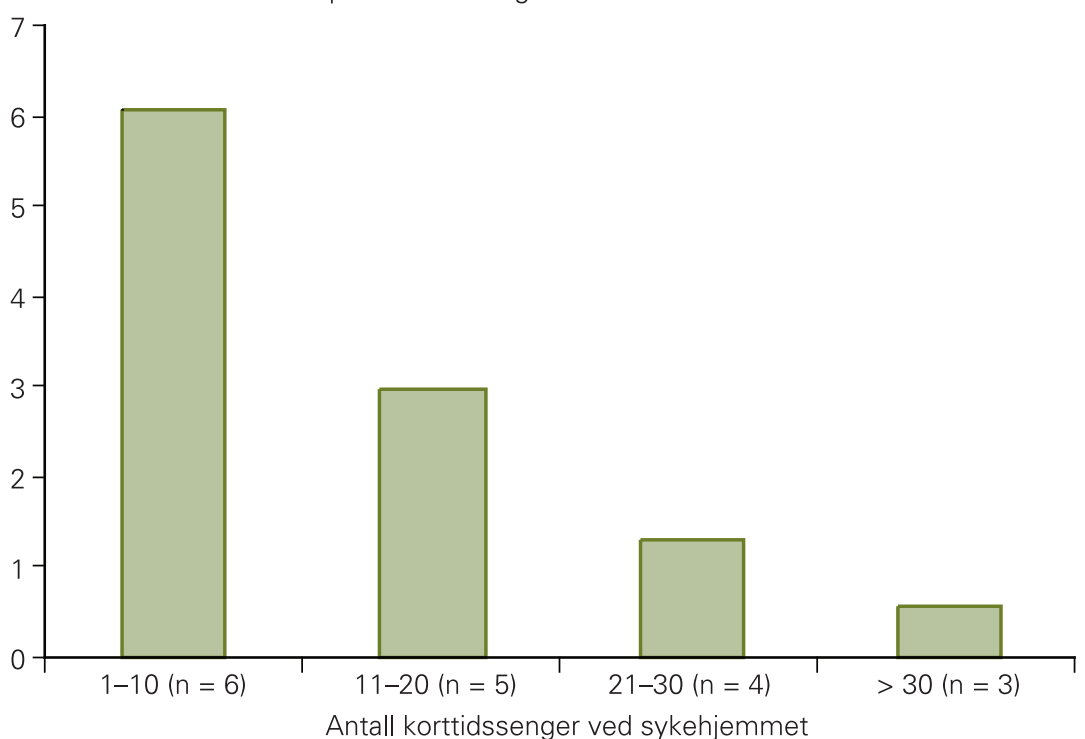

Gjennomsnittlig antall senger:

$\begin{array}{lrrrr}\text { Korttid } & 4 & 16 & 25 & 49 \\ \text { Langtid } & 39 & 83 & 94 & 94\end{array}$

Figur 2 Gjennomsnittlig antall henvendelser til vaktordningen per sykehjem fra sykehjem med korttidssenger etter antall korttidssenger

i realiteten brukes som dette ved de ulike sykehjemmene. En annen usikkerhetsfaktor er at det ikke ble registrert om henvendelsene fra sykehjemmene gjaldt korttidspasienter eller langtidspasienter.

Vi kunne ikke påvise at god legedekning ved sykehjemmene medførte færre henvendelser til vaktordningen. Den gjennomsnittlige legedekningen ved alle sykehjemmene i undersøkelsen $(0,40$ legetime per pasient per uke) var noe høyere enn landsgjennomsnittet i $2005(0,27$ legetime per pasient per uke) (10). To store sykehjem i undersøkelsen hadde mange henvendelser til tross for god legedekning, og de har begge funksjoner som medfører spesielt mange korttidspasienter.

En kartlegging fra 2001 viste at $60 \%$ av tilsynslegene i Bergen hadde avtale om at de kunne kontaktes utenom ordinær arbeidstid, men at få nyansatte tilsynsleger ønsket en slik ordning (11). Det foreligger per i dag ingen oversikt $\mathrm{i}$ kommunen over andelen tilsynsleger med slik avtale, men den er sannsynligvis betydelig lavere enn $60 \%$. Det var to store sykehjem i undersøkelsen med få henvendelser til vaktordningen, og for begge ble det rapportert om at de hadde god telefontilgjengelighet til sine faste leger.

\section{Konklusjon}

Undersøkelsen viser at sykehjemmenes bruk av vaktordningen er uavhengig av antall senger ved sykehjemmene og at god legedekning ikke medførte færre henvendelser. Bruk av ordningen bestemmes sannsynligvis av et samspill mellom flere ulike forhold, som kompetanse og erfaringsnivået til per- sonalet, prosedyrer, pleiefaktor og telefontilgjengelighet til faste leger. Det er behov for nærmere kartlegging både av de interne forholdene ved sykehjemmene, som er bestemmende for bruk av vaktordningen, og denne ordningens innvirkning på ambulanseforbruk og innleggelsefrekvens i sykehus.

Oppgitte interessekonflikter: Ingen

\section{Litteratur}

1. Halvorsen I, Meland E, Bærheim A. Bruk av legevakt $f ø r$ og etter fastlegeordningen. Tidsskr Nor Lægeforen 2007; 127: 15-7.

2. Jøsendal O, Aase S. Legevaktaktivitet før og etter innføring av interkommunal legevakt og fastlegeordning. Tidsskr Nor Lægeforen 2004: 124: 506-7.

3. Bakken C. Ønsker legevaktordning på sykehjem. Tidsskr Nor Legeforen 2008; 128: 361.

4. Bollig G. Husebø BS, Husebø S. Vakttjeneste for leger på sykehjem. Tidsskr Nor Legeforen 2008 128: $2722-4$

5. Hva foregår på legekontorene? Konsultasjonsstatistikk for 2006. Oslo: Arbeids- og velferdsdirektoratet, 2007.

6. Oslo kommune. Legevakten. Årsberetning 2006. Oslo: Oslo kommune, 2007.

7. Iveland E, Straand J. 337 sykebes $ø$ k på dagtid fra Oslo Legevakt. Tidsskr Nor Lægeforen 2004; 124 354-7.

8. Holmøy J. Pleie- og omsorgstjenester 1995-1999. Noen hovedtall basert på GERIX-data. Oslo: Statis tisk sentralbyrå, 2001

9. Forum Sykehjemsmedisin. Standard: legebemanning på sykehjem. www.sykehjemsmedisin.no (8.12.2008)

10. Normering av legetjenester i sykehjem (IS-1293). Oslo: Sosial- og helsedirektoratet, 2005.

11. Legevaktteneste for aldersinstitusjonar i Bergen. Rapport frå ei arbeidsgruppe august 2005. Bergen Bergen kommune, 2005 